\title{
A Study on the Optimization of Enterprise Financial Management Model
}

\section{under ERP Environment}

\author{
Shiqi Song ${ }^{1, a}$ \\ ${ }^{1}$ Business School of Sichuan University, Chengdu City, Sichuan Province, 610000, China \\ a email:
}

Key words: ERP System, Financial Management, Information, Innovation

\begin{abstract}
As a new modern management method, the core idea of ERP(Enterprise Resource Planning) can integrate the logistic, capital flow and information flow. Based on the author's work experience, this paper first analyzed the new characteristics of the ERP strategies in the financial management system, then studied the influence of ERP environment on the financial management of enterprises, finally put forward the strategies to optimize the financial management mode of enterprises with the aid of ERP. This article is helpful to the modern enterprise to fuse the advanced information technology and the management, and it has a certain guiding significance and application value to realize the leap of management level.
\end{abstract}

\section{Introduction}

Facing the trend of economic globalization, the enterprise must have the quick response ability. This ability needs to build an efficient information system through data, process, and decision making. ERP is a set of enterprise management system standards suggested by Gartner Group, which is a famous American computer technology consulting and evaluation group. ERP is a comprehensive and systematic management platform based on information technology. It uses modern enterprise advanced management ideas, fully integrates enterprise all resources information, and provides decision-making, planning, control and management performance evaluation. The ERP system integrates information technology and advanced management ideas, becoming the running mode of the modern enterprise, reflecting the requirements of the times. The ERP has became the cornerstone of enterprise survival and development in the information age.

\section{The New Characteristics of the ERP Strategies in the Financial Management System}

Financial management is always the core module in the ERP system. The object of financial management is the capital flow of enterprise, and it is also the measurement and reflection of the financial status and operating results of enterprises. Therefore, the financial information system has been the focus of attention of enterprises when implementing ERP. The financial management system is highly integrated with the capital flow and logistics, which achieved the integration of enterprise resource management and business process management, changed the traditional way of collecting, transmitting, sending and sharing of information, and broke through the limits of time and place. Financial management system is not only fully integrated with the internal production, business links, but also achieved a seamless link with suppliers, distributors, customers and other aspects in the supply chain. All kinds of information management flow with a high speed on the 
Intranet and Internet, and each operating department or links and stakeholders can obtain the required information at any time according to the authorization, which can greatly improve the value of the information, achieve the optimal allocation of resources and speed up the market reaction speed, so as to improve the efficiency and level of enterprise management. Because ERP realizes the centralized management of enterprise resource, all the data in the business activities are stored in the central database. Data sources is efficient and convenient and the financial management information is more comprehensive. In addition to completing the financial information and the structure of the financial management model, the financial management system can also provide support for multi-level financial management activities, for example, ERP can provide the financial statements, management reports and query functions of each management level, and provide the financial management model and analysis module that is easy to use by end users, and this provides a variety of views for the external information users, which can enable them to analyze financial data based on the authority, can also use online data analysis and processing tools for a variety of angle data modeling, so as to realize the information service of the whole supply chain, improving the scientific nature of financial decisions.

\section{The Influence of ERP Environment on the Financial Management of Enterprises}

As a part of supply chain management system, the implementation of ERP improved the supply chain system, and effectively integrated the internal information flow, logistics and capital flow, so as to realize the sharing of resources. The value chain structure of the enterprise is transformed into the financial center, and service is a ring system which is synthesized by main body, logistics, information flow and capital flow. Material flow of material flow is directly converted into the capital flow of value form, which can ensure the interaction of business information and financial information. As shown in Figure 1.

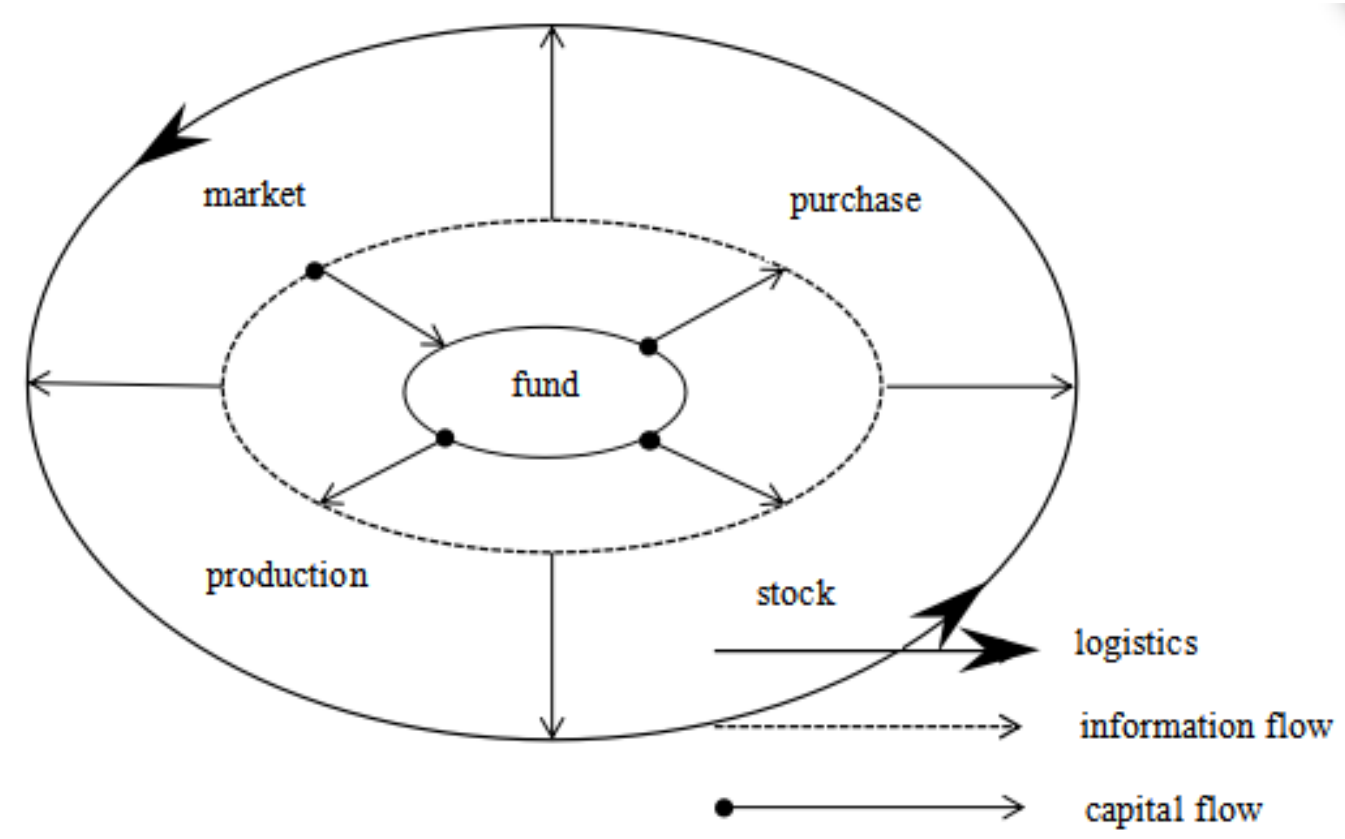

Fig.1 financial management model under ERP environment

In the ERP environment, financial information is no longer a number of simple digital symbols, it provides the actual production and circulation process of the logistics value of the business sector, which is the basis of enterprise value management. On the other hand, the efficient information transfer brought by the ERP is conducive to the realization of dynamic value management, and it 
can detect and correct value differences appearing in the specific business process in time, and ensure the accuracy and timeliness of the value information. Enterprise management information format standardization, delivery channels, and the fixed warning warning function have a significant and far-reaching impact on the enterprise financial management model.

Information highly is integrated, so it strengthened the information communication between the financial department and other business. The biggest characteristic of ERP system is information integration, the original scattered and isolated information is connected to a network for each business department to share, which can increase the level of information flow and bring the communication and coordination among the departments, so financial officer at the center of the system can monitor the value of the process of business logistics through the financial process.

The advanced information processing methods improved the efficiency and quality of financial management. The financial management under ERP environment realized the financial information transformation from post reaction to real-time processing. Financial systems and business processes become an integral part of the supply chain, which effectively expand the collection of financial information and improve the level of information processing. The implementation of ERP realized the high integration of the production, sales and inventory, which can make the resources of all aspects of the enterprise get a rational allocation and effective utilization, and it is conducive to the formation of enterprise value chain.

Value management oriented is conducive to the enterprise's capital and cost control. Financial management under ERP environment can expediently query the cost structure and various influencing factors of the enterprise, and identify high value activities that can reduce costs in the logistics process, which can provide decision basis for the managers, so as to help to improve the level of enterprise decision-making. In ERP environment, an important feature of the financial management oriented by the value management is that it can implement and strengthen the cost control function. In ERP environment, the financial management is more comprehensive, and the all related subsystems can be closely linked with the financial subsystem. The system provides a continuous monitoring of the reporting system for the establishment and implementation of the plan.

\section{The Strategies to Optimize the Financial Management Mode with the Aid of ERP}

Strengthening the concept of people-oriented to continuously improve the overall quality of financial personnel. The traditional financial management takes funds as the center, but in the present age, attaching importance to the management and development of people has become the basic trend of the development of modern financial management. Enterprise financial management should put the incentive and restraint to the people in the first place, to fully tap the potential of people, and mobilize the creativity, subjectivity and consciousness. Carrying out network technology training to improve the ability of modern information processing, sorting and analyzing, so that the staff is good at integrating all the information generated by various departments, using computer network and ERP software to handle business to realize the transformation of enterprise financial management mode in the network age.

To speed up the process of enterprise management informatization. In terms of daily business processing, enterprise implementation ERP is to make the financial department and business department supply and demand for each other. Using information technology to integrate the capital flow, logistics and information flow to realize the interactive management of enterprise internal production, inventory, management, supply and marketing and other business with financial management. Material flow in physical form is transformed to the capital flows in the form of value, 
to ensure the interaction and collaboration of business and financial information, so as to achieve the best performance of the whole system.

Recombine the business process based on the network organization structure. It needs to break the traditional pattern of one-way logistics operation in the enterprises, to realize the new mode of operation based on the logistics, capital flow and information flow. Breaking the boundaries among the enterprises and restructuring the internal work flow, establishing a process group, to realize the integration of finance, business and decision making. Reducing unnecessary intermediate links in the supply chain, to realize a full combination between the enterprise financial management and the entire supply chain.

\section{Conclusion}

Enterprise informatization has a long way to go in China, so it needs to constantly explore innovation and practice of modern financial management model in the implementation of the ERP strategy, in order to bring advanced technology and management together and optimize the financial management.

\section{Reference}

[1] Chi Lihua. Research on enterprise financial management innovation under the ERP strategy [J]. Journal of Central University of Finance and Economics, 2007,12:85-89.

[2] Jiang Haihong, Ren Jianwen. Enterprise management model and financial management function innovation based on ERP[J]. Journal of Shandong Institute of Business and Technology, 2004,01:64-67.

[3] Chang Jing, Geng Chunmei. Financial process innovation based on ERP accounting information [J]. Journal of Qiingdao University (NATURAL SCIENCE EDITION), 2009,02:71-76. (in Chinese).

[4] Wang Jianmin. The innovation of enterprise financial management mode under the ERP environment[J]. Journal of Jiaozuo Teachers College, 2009,03:50-51.

[5] Chen Youyu. Discussion on the application of ERP system in financial management [J]. Finance and Economics, 2010,12:276-277.

[6] Jiang Binghua, You Fufen. Research on the innovation of enterprise financial management based on ERP[J]. Friends of Accounting (a), 2006,07:69. 